\title{
Deslocamentos da soberania: percursos de um conceito- limite em Carl Schmitt e Giorgio Agamben
}

\author{
Displacements of the sovereignty: paths of a limit-concept \\ in Carl Schmitt and Giorgio Agamben
}

\section{Andityas Soares de Moura Costa Matos, Lorena Martoni de Freitas*}

Universidade Federal de Minas Gerais, Belo Horizonte, MG, Brasil

\section{Resumo}

Jurista e teórico-político, Carl Schmitt foi um dos grandes nomes que se propôs a pensar o problema da soberania a partir do estado de exceção. No turbulento contexto de instabilidade político-econômica que marcou a Europa no período pós Primeira Guerra Mundial, cujos Estados-nação se encontravam até então ancorados na doutrina liberal e seu modelo de governo parlamentar, Schmitt revisita a tradição de estudos acerca da soberania, afirmando a impossibilidade de se neutralizar o político, bem como a subjetividade da autoridade, como almejava o liberalismo político com seu projeto de limitar o exercício de poder soberano por meio da lei. Nesse viés, por meio da paradigmática afirmação "soberano é aquele que decide sobre o estado de exceção", Schmitt afirma a inescapabilidade do momento decisório acerca, em uma situação excepcional que identifica o inimigo público, momento esse de normalização que conforma tanto a identidade do soberano quanto a da unidade política, consubstanciando-se assim como verdadeiro

* ASMCM: Doutor, e-mail: vergiliopublius@hotmail.com; andityas@ufmg.br

LMF: Mestre, e-mail: Iorenamartonifreitas@gmail.com 
processo de instituição do direito. Doravante, à medida que a identidade do soberano é definida a partir da decisão sobre a exceção, Schmitt apresenta sua possibilidade de deslocamento para outros campos não-estatais, de modo que mesmo a decisão orientada pelo saber técnico conforma-se como soberana, desde que tenha força suficiente para identificar o inimigo público. É a partir dessa reflexão que Giorgio Agamben, filósofo italiano do século XXI, dará continuidade aos estudos sobre a soberania, radicalizando a possibilidade de seu deslocamento para as relações microfísicas de poder que se perfazem na malha social, na medida em que vê na decisão sobre a exceção não apenas um momento de conformação identitária, mas de inclusão-exclusiva da vida no ordenamento jurídico.

Palavras-chave: Soberania. Estado de exceção. Carl Schmitt. Giorgio Agamben.

\section{Abstract}

Jurist and political theorist, Carl Schmitt was one of the great names who set out to think the problem of sovereignty from the state of exception. In the turbulent context of political-economic instability that marked Europe in the post-World War I era, which nation-states were hitherto anchored in liberal doctrine and its model of parliamentary government, Schmitt revisits the tradition of studies on sovereignty, stating the impossibility of neutralizing the political as well as authority's subjectivity, while political liberalism tried to limit the exercise of sovereign power by law. In this bias, with the paradigmatic affirmation "sovereign is the one who decides on the state of exception", Schmitt affirms the inescapability of the decisive moment about an exceptional situation and that identifies the public enemy, which is a normalization moment that conforms both the identity of the sovereign and of the political unit, consubstantiating as a true process of institution of the law. Hereafter, as the identity of the sovereign is defined from the decision on the exception, Schmitt presents its possibility of displacement to other non-State fields, so that even the decision guided by a technical know-how may conform itself as a sovereign decision, provided it has sufficient strength to identify the public enemy. It is from this reflection that Giorgio Agamben, an Italian philosopher of the 21st century, will continue the studies on sovereignty, radicalizing the possibility of its displacement to the microphysical relations of power that occur in the social field, as he 
comprehends the decision on the exception not only as a moment of identity conformation, but mainly as an inclusion-exclusive structure of life in the legal order.

Keywords: Sovereignty. State of exception. Carl Schmitt. Giorgio Agamben.

\section{Introdução'}

Na história da filosofia o conceito de soberania aparece paradigmaticamente na teorização desenvolvida por Jean Bodin ${ }^{2}$ em Les six livres de la république, formulado como "a potência absoluta e perpétua de uma república" (BODIN, 1993, p. 74, trad. livre). A importância atribuída ao trabalho de Bodin se deve justamente à tentativa do autor de conceber uma noção de soberania oposta ao modelo teológico que apresentava o monarca com mero depositário do poder divino, sustentando assim a unidade da autoridade política em detrimento da sua divisão que remetia à esfera religiosa. Nesse processo, conforme observa Thomas Berns, Bodin desloca o reconhecimento da soberania de uma forma totalmente passiva para uma mais ativa, ou seja, ao invés do soberano ser identificado a partir de um simples diagnóstico com fundamentados transcendentes, seus atos e características singulares, ausentes nos demais sujeitos, passam a ser levados em consideração, de modo que "é a lógica da exceção, própria à potência absoluta, que guia Bodin" (BERNS, 2002, p. 357, trad. livre). Por conseguinte, é exatamente a capacidade de impor a lei a todos e a cada um a primeira marca da soberania (BODIN, 1993, p. 99), donde derivam todas as demais.

Não obstante, o processo de secularização iniciado por Bodin encontra suas limitações à medida que o filósofo francês sustenta que

1 Este trabalho é uma publicação parcial (e alterada para o formato de artigo) da pesquisa "Razão política securitária: a arte de governar por razões de segurança", desenvolvida em sede de Mestrado no programa de Pós-Graduação da Faculdade de Direito e Ciências do Estado da Universidade Federal de Minas Gerais e fomentada pela Fundação CAPES

2 Todavia, não podemos deixar de mencionar que a gênese do termo "soberano" remonta a Idade Média, aparecendo em discussões já nesse período com a mesma acepção adotada pelos modernos. Nesse sentido, imperioso apontarmos 0 trabalho arqueológico desenvolvido por Raquel Kritsch em "Soberania: a construção de um conceito". 
mesmo o soberano está sujeito e não deve ultrapassar as leis naturais e divinas (BODIN, 1993, p. 79). É, portanto, com Thomas Hobbes que encontramos uma reflexão voltada para enfrentar o problema da constituição da soberania de maneira ancorada na razão, com o objetivo de fundamentar e delimitar a existência e a estabilidade da autoridade sem recorrer a argumentos de cunho divino. Para tanto, o filósofo inglês elabora um convincente diagnóstico acerca da natureza humana e da vida em sociedade com o objetivo de justificar a necessidade de se estabelecer um poder soberano, lançando mão da metáfora contratualista como fundamento de legitimidade para seu exercício.

Assim, na esteira estabelecida por Bodin, Hobbes conceberá o soberano como autoridade máxima e indivisível, que detém a força e os recursos da multidão unificados em sua pessoa (HOBBES, 1974, p. 110), e será a sua vontade (e não a verdade) a fonte das leis que instituem e mantêm a ordem política (HOBBES, 1974, p. 163-178). É esse atributo que o tornará uma exceção à regra, de modo que o soberano é o único capaz de por e revogar as leis, não se encontrando submetido a elas (HOBBES, 1974, p. 166). Tal característica será então explorada quase três séculos depois por Carl Schmitt em Politische Theologie, obra que dará continuidade à tradição estabelecendo que "soberano é aquele que decide sobre o estado de exceção" (SCHMITT, 2009, p. 13).

Tendo em mente esse breve percurso histórico-filosófico, este trabalho busca esclarecer de que modo a reflexão de Schmitt acerca da noção de soberania, herdeira da tradição referenciada, destaca de maneira realista o caráter político e contingencial do direito, apresentando-o essencialmente como resultado de um arranjo de forças que se dá no âmbito fático e que tem como efeito retroativo a própria constituição do soberano. Ao sustentar a impossibilidade de se neutralizar o político localizando o poder soberano na lei conforme o projeto da doutrina liberal, o jurista alemão forneceu as ferramentas necessárias para que Giorgio Agamben ressuscitasse a questão do poder soberano no século XXI, deslocando-o para a análise das relações microfísicas de forças que se perfazem no social, concebendo assim uma nova teoria do poder. 
Nesse viés, tem-se por objetivo colocar em evidência a apropriação das reflexões schmittianas por Agamben, reflexões essas que o permitiram realizar tal deslocamento do poder soberano e afirmar sua forte presença no quadro político contemporâneo, justamente na contramão dos diagnósticos pós-Segunda Guerra Mundial que sustentavam um declínio da soberania frente aos processos de globalização e desenvolvimento dos direitos humanos (DE BOEVER, 2011, p. 181).

\section{0 soberano e 0 inevitável cerne político do direito}

No trabalho publicado em 1922, Politische Theologie, Carl Schmitt inicia o texto com uma definição paradigmática: "soberano é quem decide sobre o estado de exceção" (SCHMITT, 2009, p. 13). Como já adverte de antemão, seu objetivo não é se desfazer do tradicional esquema abstrato que define a soberania como "poder supremo e originário de mando", mas sim trabalhá-lo na dimensão de sua aplicação concreta, discutindo a identificação de "quem" exerce esse poder supremo; em outras palavras, busca-se identificar o sujeito da soberania (SCHMITT, 2009, p. 13-14). Doravante, Schmitt estabelece uma contiguidade entre estado de exceção e soberania, assumindo-a como um problema no qual se revela a questão da ação constituinte da ordem legal.

Essa dimensão constituinte da exceção foi tratada pela primeira vez pelo autor alemão em 1921 na obra Die Diktatur, na qual o estado de exceção é inscrito na questão da ditadura que, por sua vez, pode ser compreendida como "comissária" ou "soberana". A primeira funcionaria a partir da suspensão do direito com base em suas próprias normas para poder realizá-lo (sendo assim constitucional), enquanto a segunda é descrita como aquela que põe um novo direito, cria um estado propício para a imposição de uma nova Constituição, atuando assim como verdadeiro poder constituinte. Porém, é em Politische Theologie que essa separação aparece de maneira mais elaborada, uma vez que nela Schmitt apresenta a inscrição liberal do estado de exceção na Constituição como uma tentativa de neutralização do Estado e de 
sua essência política, algo impossível de se sustentar quando confrontado com a doutrina da soberania ${ }^{3}$.

Assim como o estado de exceção, o conceito de soberania é um conceito limite que concerne ao caso de necessidade ${ }^{4}$ e é por ele atualizado, de modo que a definição da soberania não pode se encontrar expressa internamente no ordenamento jurídico e referenciada na normalidade, tampouco pode o estado de exceção receber alcunhas legais como "estado de emergência", "estado de necessidade" e "estado de sítio", sendo essas apenas "débeis tentativas do Estado de Direito contornar o incontornável" (MATOS, 2012, p. 24). Afinal, a exceção é exatamente aquilo que não está previsto na norma (SCHMITT, 2009, p. 13), aquilo que a excede, mas com o que é necessário lidar de alguma forma.

El caso excepcional, el que no está previsto en el orden jurídico vigente, puede a lo sumo ser calificado como caso de extrema necesidad, de peligro para la existencia del Estado o de otra manera análoga, pero no se puede delimitar rigurosamente. Sin embargo, este caso actualiza el problema del sujeto de la soberanía, o sea, el problema mismo de la soberanía. Ni se puede señalar con claridad cuándo un caso es de necesidad, ni cabe tampoco prevenir rigurosamente lo que en tal sazón conviene si el caso de necesidad es realmente extremo y se aspira a dominar la situación. El supuesto y el contenido de la competencia son entonces necesariamente ilimitados. No se trata, por consiguiente, de una competencia en el sentido que el término tiene dentro del sistema del Estado de derecho (SCHMITT, 2009, p. 14).

3 Conforme sustenta Agamben, a teoria da soberania de Schmitt, ao se ancorar no estado de exceção, pode ser lida como uma resposta ao ensaio Zur Kritik der Gewalt de Walter Benjamin (AGAMBEN, 2004, p. 84), publicado em 1921, no qual 0 que é passível de ser compreendido como "estado de exceção efetivo" (expressão que, todavia, será utilizada por Benjamin somente em seu Über den Begriff der Geschichte, escrito em 1940) é a violência essencialmente revolucionária que depõe 0 direito. Por isso, para evitar que a teoria do estado de exceção fosse cooptada pelo discurso revolucionário, Schmitt teria substituído o binômio "poder constituído" e "poder constituinte" que usava para tratar o estado de exceção no trabalho de 1921 pela díade "norma" e "decisão".

4 Ressalta-se aqui se tratar do caso de necessidade, e não da medida legal constitucionalmente normatizada do "estado de necessidade". Nesse viés, Agamben aponta que a compreensão da exceção como força constituinte da lei e em termos de soberania pode ser retomada a partir da teoria da necessidade expressa no antigo adágio latino "necessitas legem non habet" ("a necessidade não reconhece nenhuma lei" ou "a necessidade cria sua própria lei") (AGAMBEN, 2004, p. 40), de modo que a necessidade é mais do que algo que simplesmente suspende a corrente aplicação da norma em um caso particular, sendo uma verdadeira fonte primária do direito.

Rev. Filos., Aurora, Curitiba, v. 29, n. 47, p. 575-593, maio/ago. 2017 
Conforme salienta Alexandre Franco de Sá, longe de ser neutra ou meramente descritiva, a definição de poder soberano proposta por Schmitt opõe-se radicalmente à doutrina liberal e ao normativismo jurídico, na medida em que estes objetivam eliminar a subjetividade e a arbitrariedade da autoridade que marca a arena política, substituindo-a por um procedimentalismo calcado na lei, pretensamente objetivo e limitador da autoridade política (SÁ, 2009, p. 7-8). Isso porque, para o jurista alemão, a identificação entre poder soberano e lei se revela como uma reflexão puramente abstrata, que não considera o direito tendo em vista sua aplicação a uma situação concreta, propondo antes um estudo do direito sem a efetivação do direito (SÁ, 2009, p. 10).

Se ordinariamente o direito se perfaz como ordem que se remete continuamente a si mesma operando em situações normais, a norma pura não tem capacidade de submeter a realidade exceptiva a seus mandados. É preciso uma vontade de conformar a realidade (PRIETO, 2012, p. 111), vontade essa fundada na exceção, essa força da vida que nos faz saltar fora do sistema mecânico de repetição que caracteriza a normalidade (SCHMITT, 2009, p. 20).

Nesse viés, a exceção não é um fenômeno que se encontra no âmbito do meramente factual, em uma esfera suprajurídica, mas sim um momento de indistinção entre criação e aplicação do direito (MATOS, 2012, p. 21), um "espaço apocalíptico do direito porque o extermina ao revelá-lo" (MATOS, 2012, p. 40). Operando à margem do direito, ela se dirige rumo a ele, e é por isso que Schmitt insere o estado de exceção no limite da ordem jurídica como alavanca que permite seu funcionamento, e não como mera peça no seu interior normativo como intentava a doutrina liberal. "Estar-fora e, ao mesmo tempo, pertencer: tal é a estrutura topológica do estado de exceção", donde deriva o conceito schmittiano de soberania (AGAMBEN, 2004, p. 57). Por meio da exceção "o poder, a soberania e a ordem recuperam a distinção originária anterior ao estabelecimento do estado político organizado" (PRIETO, 2012, p. 139), e é por isso que se pode dizer que no interior do direito habita constantemente a decisão soberana. 
É exatamente a capacidade de se desfazer das normas jurídicas vigentes para lidar com uma situação excepcional e restabelecer a ordem do atributo mais genuíno da soberania, e o que a caracteriza como poder originário. Assim, a tentativa de identificar o soberano (e o estado de exceção) no interior de uma norma jurídica constituiria uma falsa solução para o problema, que antes o obscurece em vez de solucioná-lo. Afinal, por mais que a norma jurídica tente apontar o responsável por lidar com a situação excepcional, enumerando suas faculdades extraordinárias, determinando uma limitação para seu tempo de exercício ou como se deverá proceder nesse caso, será sempre necessária uma decisão eminente que determine e reconheça se tratar de uma situação excepcional autêntica, de modo que essa decisão está fora do ordenamento jurídico normalmente vigente sem, todavia, deixar de lhe pertencer. Por isso, a decisão soberana é uma decisão-limite, pois ancorada na normalidade é capaz de reconhecer e nomear o excepcional que se encontra fora dela, estabelecendo um marco que é fim e começo ao mesmo tempo: fim da ordem atual e começo daquilo que deve ser ordenado. “É essa inevitável remissão da norma ao poder, à autoridade que decide a sua aplicação, que Schmitt procura expressar através do seu decisionismo" (SÁ, 2009, p. 11).

Desse raciocínio conclui-se que toda ordem e normalidade repousam, em última instância, sobre uma decisão e não sobre uma norma (SCHMITT, 2009, p. 16), o que faz do normativismo jurídico um decisionismo velado:

En un instante, la decisión se hace independiente de fundamentación argumental y adquiere valor propio. En la teoría de los actos irregulares del Estado muéstrase este principio en toda su significación teórica y práctica. La decisión irregular y defectuosa produce efectos jurídicos. La decisión irregular tiene un elemento constitutivo precisamente por su irregularidad. Pero la idea misma de la decisión implica que no pueda haber decisiones absolutamente declaratorias. Considerado desde el punto de vista del contenido de la norma básica, es ese elemento constitutivo y específico de la decisión algo completamente nuevo y extraño. Normativamente considerada la decisión nace de la nada. La fuerza jurídica de la decisión es harto distinta del resultado de su fundamentación (SCHMITT, 2009, p. 32). 
Nesse viés, Schmitt compara o estado de exceção ao milagre religioso, lançando mão da intervenção divina direta como analogia para explicar a decisão soberana (SCHMITT, 2009, p. 37). Simbolicamente o soberano é apresentado não como o Deus já previamente aceito, mas como Aquele que assim se constitui exatamente por meio da prova efetiva de seu poder divino, a partir de sua "intervenção existencial" (STRONG, 2007, p. xiv). Essa construção leva Schmitt a afirmar que "el derecho es siempre derecho de una situación" (SCHMITT, 2009, p. 18), situação essa criada e garantida, em sua totalidade, pelo poder soberano. Por isso é preciso pensar o direito considerando sua essência política, contingente e conjuntural, algo que a teoria pura do direito de Kelsen, ao se ancorar no princípio da segurança jurídica e afirmar a primazia da norma, é incapaz de fazer.

O posicionamento de Schmitt o leva a construir uma teoria realista do Estado baseada em uma forte definição e afirmação do "político", tomado como destino inescapável do ser humano 5 (STRAUSS, 2007, p. 110). Assim, em Der Begriff des Politischen, publicado originalmente em 1927 e republicado com significativas alterações em 1932, o jurista principia afirmando que o político possui critérios próprios de definição, balizados pela díade amigo/inimigo (SCHMITT, 1992a, p. 51). Trata-se, portanto, de defini-lo tendo em vista o momento em que o inimigo é assim reconhecido, determinando assim o agrupamento dos amigos aliados contra ele e constituindo uma relação de antagonismo entre "nós" (o "mesmo") e "eles" (o "outro") (SCHMITT, 1992a, p. 52). Em outras palavras, "a constituição de uma situação normal implica a exclusão de situações alternativas" (FERREIRA, 2004, p. 102), de modo que é a partir do reconhecimento do inimigo como radicalmente tudo aquilo que "não se é" que a própria identidade daquilo "que se é" se torna definida, trazendo à luz então uma unidade política que será

5 No entanto, a afirmação do político como condição do ser humano feita por Schmitt não deve ser confundida com aquela enunciada por Aristóteles (e rechaçada por Hobbes). Como explicaremos mais adiante, o político aparece em Schmitt necessariamente balizado pelo conflito inerente aos agrupamentos de amigos/inimigos, ou seja, de modo diverso do expresso no pensamento aristotélico, no qual o político é concebido visando às noções de sociabilidade e de vida em comum. Em outras palavras, se em Aristóteles o político é um dado ontológico, proveniente da "natureza" humana, em Schmitt ele apresenta um caráter formal, dependente do grau de intensidade de uma oposição. 
espaço da normalidade. Esta, por conseguinte, aparece como existencialmente ameaçada.

À medida que o político é compreendido como um campo que se constitui a partir de um antagonismo existencial referente à situação excepcional da guerra, a noção de soberania emerge da decisão que identifica o inimigo ${ }^{6}$ e constitui a unidade normativa chamada de Estado (SCHMITT, 1992a, p. 65). Em outras palavras, é a nomeação da ameaça existencial que aparece como "exceção" que identifica o soberano enquanto poder originário que instaura a normatividade, ou seja, a ordem política dos amigos e sua segurança, tendo em vista o que será deixado de fora dela: o inimigo ${ }^{7}$.

$\mathrm{Na}$ operação reflexiva em que o inimigo desempenha o papel fundamental para uma autorreferência identitária substancial reside então o caráter ordenador da decisão soberana. Por isso a diferenciação entre amigo/inimigo que determina o político possui o sentido de "designar o grau de intensidade extrema de uma ligação ou separação, de uma associação ou dissociação" (SCHMITT, 1992a, p. 52), movimento este que se realiza fazendo referência a quaisquer critérios - morais, estéticos, econômicos etc. - para se justificar, desde que o grau de oposição atinja um nível máximo em que a existência da comunidade de

6 Essa nomeação do inimigo como momento crucial para se conceber a soberania se liga à tradicional competência do soberano para dispor sobre a vida e a morte expressa no antigo jus belli - ou no direito de declaração de hostis -, a partir do qual ao soberano é atribuída a possibilidade de se exigir que os sujeitos sacrifiquem sua vida na guerra em nome da existência da ordem política e do funcionamento tranquilo do Estado no qual encontram a segurança da normalidade (SCHMITT, 1992a, p. 74).

70 conceito de inimigo construído por Schmitt deve ser tomado em seu sentido concreto e não como metáfora ou símbolo, muito menos como mero adversário ou oponente em um âmbito de discussão e debate (SCHMITT, 1992a, p. 54). Tratase de uma ameaça existencial que, tendo sido comumente reconhecida como advinda do "inimigo" por um número de sujeitos coletivos (ou "povos"), propulsiona seu agrupamento enquanto "amigos". Assim, o inimigo se apresenta como um sujeito coletivo que combate e ameaça outro sujeito necessariamente coletivo, constituindo-se, portanto, sempre como um inimigo público, não se confundindo com o mero adversário particular (SCHMITT, 1992a, p. 55). Isso se dá porque 0 conceito do político refere-se à identificação de um inimigo comum e corresponde a um âmbito real de possibilidade de luta. Desde que 0 inimigo represente efetivamente uma ameaça existencial (e isso implica, como salienta o pensador alemão, a possibilidade de um combate armado), a relação política balizada pelo modelo da guerra se efetiva tanto entre unidades políticas organizadas quanto no interior de uma mesma unidade organizada. Nesses termos, tendo em vista que a função de um Estado consiste, sobretudo, em produzir no seu interior um status de tranquilidade, segurança e ordem, com o objetivo de se criar uma situação normal, essa necessidade leva o Estado, enquanto unidade política, a determinar por vezes também um inimigo interno que ameaça a existência dessa ordem.

Rev. Filos., Aurora, Curitiba, v. 29, n. 47, p. 575-593, maio/ago. 2017 
amigos - os "mesmos" - esteja ameaçada. Ou seja, essa distinção específica do político fornecida pelo autor não é derivável de outros critérios (como bom/mau, que baliza o campo moral, ou o belo/feio, que diz respeito ao campo estético), mas se constitui de maneira independente, já que não se fundamenta nas demais oposições nem se reporta a elas (SCHMITT, 1992a, p. 51-52):

O inimigo político não precisa ser moralmente mau, não precisa ser esteticamente feio; não tem que surgir como concorrente econômico, podendo talvez até mostrar-se proveitoso fazer negócio com ele. Pois ele é justamente o outro, o estrangeiro, de modo que, bastando à sua essência que, num sentido particularmente intensivo, ele seja existencialmente algo outro e estrangeiro, de modo que, no caso extremo, há possibilidade de conflitos com ele, os quais não podem ser decididos mediante uma normatização geral previamente estipulada, nem pelo veredicto de um terceiro "desinteressado", e, portanto, "imparcial" (SCHMITT, 1992a, p. 52).

Não obstante, o político pode extrair sua força dos mais variados setores sociais, de modo que nada impede que contraposições religiosas, econômicas e outras se tornem uma contraposição política, desde que o antagonismo atinja força suficiente para agrupar os sujeitos em amigos/ inimigos visando a um horizonte de luta (SCHMITT, 1992a, p. 63).

Logo, se por um lado Schmitt rejeita a perspectiva normativista, evidenciando a inescapável necessidade de uma vontade subjetiva consubstanciada em decisão para que a norma seja aplicada, por outro lado o jurista rejeita o argumento de que essa decisão possa ser obtida de maneira neutra, como desdobramento necessário de um procedimento técnico-jurídico. Conforme salienta Bernardo Ferreira, a afirmação do político que encontramos na obra de Schmitt implica dizer que inclusive os conhecimentos são, inevitavelmente, politicamente posicionados, de modo que o autor alemão recusa a existência "de um ponto de vista arquimediano, que permita alcançar uma perspectiva privilegiada, destacada das condições em que se dá a luta política" (FERREIRA, 2004, p. 38-39). Nesses termos, a enunciação da verdade oriunda do saber técnico não dissolve a subjetividade de um grupo dominante no espaço 
da autoridade, mas apenas troca os sujeitos que decidem. Em vez de substituir a soberania, a técnica serve antes como instrumento e arma de determinado grupo no exercício do poder, e "justamente porque ela serve a qualquer um, ela não é neutra" (SCHMITT, 1992b, p. 116).

Newton Bignotto observa que essa reflexão sobre a soberania "nega aos sistemas jurídicos um conteúdo imanente que os livraria da contingência que assola a vida política" (BIGNOTTO, 2008, p. 405), de modo que estes são definidos politicamente pela decisão soberana que identifica o inimigo. Porém, isso não significa que Schmitt assuma o direito como idêntico a qualquer tipo de exercício de poder arbitrário e desvinculado. Assim como o inimigo é concebido como "inimigo público", determinante da identidade de um povo e de uma nação, a decisão soberana possui uma dimensão estatal capaz de engajar múltiplos indivíduos em uma unidade política. Todavia, não há nenhuma referência a um valor, direito fundamental ou natural intrínseco que sustente o exercício desse atributo da decisão. Sua base é o arranjo de forças que se dá na realidade prática, na própria eficácia da decisão enunciada que então se faz válida, validade essa que, aqui, não diz respeito a nenhuma norma anterior, nem a uma anuência tácita ou explícita de súditos naturalmente livres, mas sim à sua pura força enquanto decisão. Por isso podemos afirmar que o realismo schmittiano acerca do conceito de soberania foge a qualquer ideia de representação de interesses ou de acúmulo de poderes que dependa daqueles cedidos por outrem, conforme sugerido nas teorias contratualistas ${ }^{8}$, encontrando-se fortemente atrelado ao exercício do poder que se perfaz na decisão fática sobre a exceção, decisão essa que aniquila e instaura a ordem jurídica, configurando aquele ponto de encontro entre direito e política que as doutrinas jurídicas liberais tanto tentaram apagar.

8 Todavia, não podemos deixar de mencionar aqui a interpretação do trabalho de Hobbes feita por Schmitt que, na contramão dos tradicionais estudos alemães na época que liam o filósofo inglês como um percursor do liberalismo moderno, apresenta-o como um clássico representante do decisionismo, ressaltando o personalismo da figura absoluta do soberano cuja palavra é a fonte da lei e da justiça, já que "os pactos sem a espada não passam de palavras, sem força para dar qualquer segurança a ninguém" (HOBBES, 1974, p. 107). Nesse viés, Schmitt se desfaz do processo contratual de constituição do Estado soberano apresentado no Leviathan, e resgata exatamente aquilo que foi dispensado pela neutralização da doutrina liberal: seu aspecto personalista $\mathrm{e}$ seu poder ilimitado que origina e mantém toda ordem e sistema jurídico (SCHMITT, 2008, p. 94). 


\section{0 deslocamento do conceito de soberania}

Ao afirmar a inescapabilidade do político, Schmitt busca evidenciar que mesmo quando o governo liberal se fundamenta na técnica jurídica e na expertise da economia política para justificar seus atos, o que ocorre não é o desaparecimento da arbitrariedade típica do poder soberano, mas sim seu deslocamento para outro sujeito (no caso, o detentor de um saber específico) que passa a decidir sobre a exceção. Porém, assim como não é qualquer adversário ou criminoso que assume a alcunha de "inimigo", também não é qualquer faculdade extraordinária ou medida de polícia que pode ser considerada um exercício do poder soberano, já que esse é definido a partir da decisão sobre o estado excepcional, por sua vez caracterizado pela suspensão da ordem jurídica vigente (SCHMITT, 2009, p. 17).

Essa compreensão da soberania exposta por Schmitt e sua possibilidade de deslocamento levará Giorgio Agamben a enunciar que a essência da soberania "não deve ser propriamente definida como monopólio da sanção ou do poder, mas como monopólio da decisão" (AGAMBEN, 2007, p. 24), decisão esta que cria o direito interiorizando a vida em seu sistema na medida em que interdita e exclui aquilo que é excepcional a ele. Nesse viés, levando em consideração a penetração da técnica na esfera da decisão política, a tese do filósofo italiano permite que o poder soberano seja identificado tanto no alto escalão das autoridades políticas quanto nos múltiplos agentes da administração pública ou até mesmo naqueles capazes de direcionar ambos na atividade de governo, possibilitando assim que o conceito de soberania seja pensado em termos microfísicos.

Partindo da tese schmittiana que entrelaça o conceito de soberania ao de estado de exceção, Agamben reflete sobre a paradoxal existência topológica do soberano, que está ao mesmo tempo dentro e fora do ordenamento jurídico, pois na medida em que o soberano possui o poder legal de suspender a validade da lei, ele se coloca legalmente fora dela (AGAMBEN, 2007, p. 23). Porém, a diferença em relação às teses de Schmitt acerca da soberania se dá na medida em que o filósofo italiano concebe o estado de exceção não como simples suspensão 
espaço-temporal da ordem jurídica ou um momento de plenitude de poderes, mas sim como um vazio que interrompe o direito, uma zona de anomia, um topos complexo e paradoxal de indistinção entre exceção e regra, entre transgressão e execução da lei, entre dentro e fora do direito que vigora sem conteúdo ou significado específico. A partir daí, Agamben conclui que o poder soberano, definido como "lei viva", possui uma natureza essencialmente anômica (AGAMBEN, 2004, p. 106), de modo que a decisão soberana não é "a expressão da vontade de um sujeito hierarquicamente superior a qualquer outro, mas (aquilo que) representa a inscrição, no corpo do nómos, da exterioridade que o anima e lhe dá sentido" (AGAMBEN, 2007, p. 33).

Em outras palavras, é a função exclusivo-inclusiva da decisão que "encerra o que está fora", designando-o como algo exterior a si mesmo e estabelecendo um limiar entre aquilo que está, simultaneamente, dentro e fora do ordenamento jurídico, o que indica a essência da soberania (AGAMBEN, 2007, p. 34). Nesses termos, o que está fora é exatamente a vida biológica despida de sua roupagem normativa, de modo que o poder soberano não se determina a partir de uma autoridade subjetiva específica, nem se esgota no mero exercício da repressão, mas se caracteriza essencialmente pela exclusão-inclusiva que produz "vida qualificada" ao implicar a vida nua na esfera política, sendo este seu núcleo originário (AGAMBEN, 2007, p. 14):

Se a exceção é a estrutura da soberania, a soberania não é, então, nem um conceito exclusivamente politico, nem uma categoria exclusivamente jurídica, nem uma potência externa ao direito (Schmitt), nem a norma suprema do ordenamento jurídico (Kelsen): ela é a estrutura originária na qual o direito se refere à vida e a inclui em si através da própria suspensão. Retomando uma sugestão de Jean-Luc Nancy, chamemos bando (do antigo termo germânico que designa tanto a exclusão da comunidade quanto o comando e a insígnia do soberano) a esta potência (no sentido próprio da dýnamis aristotélica, que é sempre também dýnamis mè energeîn, potência de não passar ao ato) da lei de rnanter-se na própria privação, de aplicarse desaplicando-se. A relação de exceção é uma relação de bando. Aquele que foi banido não é, na verdade, simplesmente posto fora da lei e indiferente a esta, mas é abandonado por ela, ou seja, exposto e colocado em risco no limiar em que vida e direito, externo e interno, se confundem. Dele não 
é literalmente possível dizer que esteja fora ou dentro do ordenamento (por isto, em sua origem, in bando, a bandono significam em italiano tanto 'a mercê de' quanto 'a seu talante, livremente', como na expressão correre a bandono, e bandito quer dizer tanto 'excluído, posto de lado' quanto 'aberto a todos, livre', como em mensa bandita e a redina bandita). É neste sentido que o paradoxo da soberania pode assumir a forma: 'não existe um fora da lei'. A relação originária da lei com a vida não é a aplicação, mas o abandono. A potência insuperável do nómos, a sua originária 'força de lei', é que ele mantém a vida em seu bando abandonando-a (AGAMBEN, 2007, p. 35-36).

Se Schmitt conceitua o político a partir da linha divisória entre amigo-inimigo, Agamben transfere o conceito para a linha de separação entre vida nua e vida juridicamente qualificada (LEMKE, 2005, p. 5), indicando que toda política é, em si mesma, biopolítica, na medida em que se fundamenta no par exclusão-inclusão da vida, cujo produto é a vida qualificada e o subproduto a vida nua. Assim, apesar da ideia do inimigo ser sempre necessária para a constituição identitária, de modo que ele não pode nunca ser completamente exterminado, antes mesmo de sua nomeação como tal o que encontramos são sujeitos concretos submetidos ao risco da violência e da morte, abandonados pelo direito constituído para proteger os indivíduos qualificados como cidadãos. Por isso, o poder de morte do soberano concebido por Agamben à luz do estado de exceção não se expressa radicalmente como um exercício do direito de morte, nem como um direito análogo à legítima defesa do Estado, mas como pura exposição da vida nua à violência da anomia, na medida em que ela é inclusivamente excluída da normalidade.

Nesses termos, o conceito de soberania de Agamben, na mesma esteira traçada por Schmitt, também não pode ser apreendido em termos de legitimidade ou de processos constituintes calcados na vontade de sujeitos de direito ou em seus supostos direitos naturais e/ou pré-políticos, pois ela não emerge de um contrato, mas sim da lógica da exceção no momento em que se decide sobre ela (GENEL, 2004, p. 8). Todavia, se por um lado vemos Schmitt sustentar que não é qualquer decisão extraordinária ou medida de polícia que pode ser considerada um exercício do poder soberano, já que esse é assim definido pela capacidade 
de suspender totalmente a ordem jurídica vigente (SCHMITT, 2009, p. 17), constituindo a identidade unitária do Estado político, a ênfase que Agamben dá ao cerne biopolítico da decisão soberana que expõe a vida à morte lhe permite pensar o exercício do poder soberano de maneira deslocada, identificando-o fora do centro político no qual normalmente ele se encontra localizado. A partir desse ponto, o filósofo perfaz uma síntese entre poder soberano e os múltiplos mecanismos de poder que se constituem na malha social, algo que, além de sustentar a constante presença da soberania na política contemporânea, conforma-se como uma verdadeira teoria do poder (GENEL, 2004, p. 16-19).

Lançando mão da ideia de "campo" enquanto porção de território qualquer que emerge por um tempo indeterminado como exceção à normalidade jurídica e no qual se suspende o direito ao mesmo tempo em que ele é instituído e aplicado (AGAMBEN, 2007, p. 176-177), Agamben sugere que aquele que decide nesse espaço é compreendido como soberano, de modo que tal categoria é descentralizada pelo filósofo italiano e passa a poder ser assumida por diferentes agentes no interior dos atuais Estados de Direito. Assim, são citados os casos em que imigrantes clandestinos foram provisoriamente aglomerados no estádio de Bari em 1991 pela polícia italiana e as zones d'attente nos aeroportos internacionais franceses, nas quais são retidos estrangeiros que clamam pelo reconhecimento da condição de refugiados, exemplos nos quais é possível identificar a materialização de um estado de exceção, quando o fato se transforma em direito e o direito em fato, na medida em que a normalidade, se produzida, o é exclusivamente pela civilidade e pelo senso ético da polícia que ali age como soberana (AGAMBEN, 2007, p. 181). Essa descentralização fica ainda mais clara quando nos voltamos para um ensaio originalmente publicado em 1992 com o título Polizia sovrana. Expressamente inspirado no texto Zur Kritik der Gewalt de Walter Benjamin, no qual o filósofo alemão apresenta a polícia como intolerável representação do poder soberano, já que a violência por ela praticada é, ao mesmo tempo, garantidora e instituinte do direito (BENJAMIN, 2011, p. 135-136), Agamben sustenta que a soberania ingressou de maneira definitiva na polícia, uma vez que sua função é exatamente aquela que evidencia a proximidade entre norma e exceção que caracteriza o poder soberano (AGAMBEN, 2015, p. 51-52). 


\section{Considerações finais}

As discussões acerca da soberania nas obras de Carl Schmitt e Giorgio Agamben conformam um campo de estudos e debates deveras extenso. Por isso, este artigo não teve por objetivo esgotar o assunto em questão, mas sim apresentar certo recorte analítico que nos permite evidenciar o modo pelo qual os estudos schmittianos sobre a questão do soberano foram apropriados e reelaborados sob a forma de uma teoria do poder nos trabalhos de Giorgio Agamben.

A partir da possibilidade apontada por Schmitt de a soberania se deslocar para outras esferas que não a estatal, na medida em que a decisão sobre o inimigo (ou sobre a vida nua/qualificada) é transferida para um grupo de experts que enfraquece o Estado em sua unidade, vemos Agamben radicalizar essa tese, de modo que em seu diagnóstico a exclusão perpetrada pelo "Estado" e pelo "poder soberano" corresponde tanto àquela exercida pelo alto escalão de poderes quanto pelos múltiplos agentes da administração pública ou até mesmo por aqueles capazes de direcionar ambos na atividade de governo.

Nesse sentido, foi possível sustentar que o projeto agambeniano traça um novo campo de reflexão ao lado da tradição filosófica da soberania, propondo uma perspectiva que não estabelece um ponto fixo para o exercício do poder soberano, mas que o amplia, permitindo que este seja pensado em termos microfísicos.

\section{Referências}

AGAMBEN, G. Estado de exceção. Trad. Iraci D. Poleti. São Paulo: Boitempo, 2004.

AGAMBEN, G. Homo sacer: o poder soberano e a vida nua. Trad. Henrique Burigo. Belo Horizonte: Universidade Federal de Minas Gerais, 2007.

AGAMBEN, G. Polícia soberana. In: Meios sem fim: notas sobre a política. Trad. Davi Pessoa. Belo Horizonte: Autêntica, 2015. p. 51-52 
BENJAMIN, W. Para uma crítica da violência. In: Escritos sobre mito e linguagem (1915-1921). Trad. Ernani Chaves, São Paulo: Editora 34, p. 121-156, 2011.

BERNS, T. Souveraineté, droit et gouvernementalité. Centre de Philosophie du Droit de l'Université Libre de Bruxelles, n. 46, p. 351-364, 2002. Disponível em: $<$ https://www.academia.edu/23312593/Souverainet\%C3\%A9_droit_et_gouver nementalit\%C3\%A9?auto=download $>$. Acesso em: 13 jan. 2017.

BIGNOTTO, N. Soberania e exceção no pensamento de Carl Schmitt. Kriterion, Belo Horizonte/MG, n. 118, p. 401-415, 2008. Disponível em: <http://www.scielo.br/scielo.php?script=sci_arttext\&pid=S0100-512X2008000200007>. Acesso em: 21 dez. 2016

BODIN, J. Les six liores de la république (Ebook). Paris: Librairie Générale Française, 1993. Disponível em: http://classiques.uqac.ca/classiques/bodin jean/six_livres_republique/bodin_six_livres_republique.pdf $>$. Acesso em: 13 jan. 2017.

DE BOEVER, A. Sovereignty. In: MURRAY, A.; WHYTE, J. (ed.). The Agamben dictionary. Edinburgh: Edinburgh University, 2011. p. 180-182

FERREIRA, B. O risco do político: crítica ao liberalismo e teoria política no pensamento de Carl Schmitt. Belo Horizonte: Universidade Federal de Minas Gerais, 2004.

GENEL, K. Le biopouvoir chez Foucault et Agamben. Methodos. Savoir et textes, n. 4, p. 1-26, 2004. Disponível em: <https://methodos.revues.org/131>. Acesso em: 15 jan. 2017.

HOBBES, T. Leviatã. Trad. João Paulo Monteiro e Maria Beatriz Nizza da Silva. São Paulo: Abril Cultural, 1974.

KRITSCH, R. Soberania: a construção de um conceito. São Paulo: Humanistas, 2002.

LEMKE, T. A zone of indistinction. A critique of Giorgio Agamben's concept of biopolitics. Outlines, n. 1, p. 3-13, 2005. Disponível em: <https://ojs.statsbiblioteket.dk/index.php/outlines/article/view/2107>. Acesso em: 15 jan. 2017. 
MATOS, A. S. M. C. Nomos pantokrator: apocalipse, exceção e violência. In: CARDOSO, R. C.; MATOS, A. S. M. C. (coords.). Estado de exceção e biopolítica. Belo Horizonte: Initia Via, 2012. p. 11-66.

PRIETO, E. Poder, soberania e exceção: uma leitura de Carl Schmitt. Trad. Andityas Soares de Moura Costa Matos e Pedro Savaget Nascimento. Revista Brasileira de Estudos Políticos. Belo Horizonte, n. 105, p. 101-150, 2012. Disponível em: <http://www.pos.direito.ufmg.br/rbep/index.php/rbep/article/download/ P.0034-7191.2012v105p101/184>. Acesso em: 21 dez. 2016.

SÁ, A. F. de. Do decisionismo à teologia política: Carl Schmitt e o conceito de soberania. Covilhã: LusoSofia, 2009. Disponível em: <http://www.lusosofia.net/ textos/sa_alexandre_franco_de_do_decisionismo_a_teologia_politica.pdf $>$. Acesso em: 09 jan. 2017.

SCHMITT, C. A era das neutralizações e despolitizações. In: SCHMITT, C. O conceito do político. Trad. Álvaro L. M. Valls. Petrópolis: Vozes, 1992b. p. 106-120. SCHMITT, C. O conceito do político. Trad. Álvaro L. M. Valls. Petrópolis: Vozes, 1992a.

SCHMITT, C. El Leviatán en la doctrina del Estado de Thomas Hobbes. Trad. Antonella Attili. Ciudad de México: Fontamara, 2008.

SCHMITT, C. Teología política. Trad. Francisco Javier Conde e Jorge Navarro Pérez. Barcelona: Trotta, 2009.

STRAUSS, L. Notes on Carl Schmitt, The concept of the political. In: SCHMITT, C. The Concept of Political. Trad. George Schwab. Chicago: University of Chicago, 2007. p. 97-122.

STRONG, T. B. Foreword. In: SCHMITT, C. The concept of the political. Trad. George Schwab. Chicago: University of Chicago, 2007, p. ix-xxxi.

Recebido: 13/03/2017

Received: 03/13/2017

Aprovado: $12 / 07 / 2017$

Approved: 07/12/2017 